\title{
Respiratory Care for Myasthenic Crisis
}

\author{
Ping-Hung Kuo and Pi-Chuan Fan \\ National Taiwan University \\ Hospital Taiwan \\ Taiwan
}

\section{Introduction}

Myasthenic crisis is a life-threatening complication of myasthenia gravis (MG) that is traditionally defined as weakness of respiratory muscles that is severe enough to require intubation or artificial respiratory support (Jaretzki et al., 2000). Rapid and marked increase in limb and bulbar weakness without respiratory failure, however, should probably be also defined as crisis in a myasthenic patient. Although it is potentially lifethreatening, the mortality rate has declined dramatically with better and more aggressive care in the intensive care unit (ICU) and the widespread use of immunotherapies (Varelas et al., 2002; Thomas et al., 1997). Respiratory management of these patients, however, is very challenging due to the fluctuating nature of the disease. Assiduous attention to respiratory care provides support of the patient, allowing time for therapy of the underlying myasthenia to be effective. There are deficiencies in current services for myasthenic crisis in that the ICU physicians not being expert respiratory specialists, and physicians managing mechanical ventilation not experienced in neurologic aspects of these patients.

This chapter reviews the respiratory dysfunction in myasthenic crisis and discusses issues related to respiratory care in these patients, including airway management, mechanical ventilation and extubation outcome.

\section{Epidemiology}

Myasthenic crisis occurs in 15 to $20 \%$ of patients with MG during their lifetime (Phillips, 2004 ). It usually occurs during the course of first symptomatic presentation in the young and later in the course of the disease in the elderly. The median time to first myasthenic crisis from onset of MG ranges from 8 to 12 months (Thomas et al., 1997; Rabinstein et al., 2005). However, crisis may be the initial presentation of MG in one-fifth of patients (Rabinstein et al., 2005;. O'Riordan et al., 1998). Overall, women are twice as likely as men to be affected. There is a bimodal distribution of myasthenic crisis, with an early peak prior to age 55 affecting women 4:1, whereas a later peak after age 55 affecting women and men equally (Thomas et al., 1997). The average age of admission with crisis is 59 years (Wendell et al., 2011). Pregnancy is associated with an aggravation of myasthenia gravis in approximately a third of all women and myasthenic crisis in pregnancy carries high perinatal mortality (Plauche, 1991). 
The incidence of crisis remains stable from 1960s to 1990s (Cohen and Younger, 1981). Recently, an increasing incidence of MG, especially in the elderly population, has been observed in some countries (Pakzad, 2011), and the incidence of anti-acetylcholine receptor (AChR) seropositivity in the $\geq 65$ age group has increased at a significantly greater rate than the rate of increase in the younger people. It is very rare for patients with myasthenia to need long-term invasive or noninvasive ventilator support, although that need is slightly more common in patients with muscle specific tyrosine kinase (MuSK) antibodies (MuSK$\mathrm{MG}$ ) as opposed to AChR antibodies (AChR-MG).

\section{Precipitants of myasthenic crisis}

Myasthenic crisis may be precipitated by a variety of factors, most often a concurrent infection (Mayer, 1997; Wendell and Levine, 2011' Thomas et al., 1997). Although patients with MG can develop any common infection that can result in decompensation, the most likely source of infection is pulmonary. One series documented infection in $38 \%$ of patients presenting with myasthenic crisis. The most common cause was bacterial pneumonia, followed by a bacterial or viral upper respiratory infection (Thomas et al., 1997). Other precipitants can be surgery, menstruation, pregnancy, childbirth, or tapering of immunosuppressive medications, exposure to temperature extremes, pain, sleep deprivation, and physical or emotional stress. The precipitant may not be found in up to one-third of cases (Mayer, 1997; Thomas et al., 1997; O'Riordan et al., 1998). In addition, crisis can occur spontaneously as part of the natural history of MG itself (Thomas et al., 1997; O'Riordan et al., 1998; Juel, 2004). A number of drugs can increase the weakness in myasthenia and should be considered as possible precipitants in this setting. This is of more concern with certain antibiotics (aminoglycosides, erythromycin and azithromycin), cardiac drugs ( $\beta$-blockers, procainamide, and quinidine), and magnesium (Wendell and Levine, 2011). Although corticosteroids can be used in the treatment of MG, initial treatment with prednisone led to an exacerbation of MG in almost half of patients in 1 series (Pascuzzi et al., 1984). The incidence of myasthenic crisis resulting from corticosteroids ranges from 9 to $18 \%$ (Pascuzzi et al.,1984; Bae et al., 2006). Therefore, initiation of corticosteroid therapy for the treatment of MG should always occur in a hospital setting, where respiratory function can be monitored (Pascuzzi et al, 1984). Predictors of exacerbation from prednisone include older age, lower score on the Myasthenia Severity Scale, and bulbar symptoms (Bae et al., 2006).

\section{Pathophysiology and clinical presentations}

The respiratory failure in myasthenic crisis can be of either the hypoxemic or the hypercapnic form, and may result from the combination of poor airway protection, inadequate secretion clearance and hypoventilation (Juel, 2004; Borel et al., 1993; MierJedrzejowicz et al., 1988). Muscle weakness in AchR-MG tends to initially affect the intercostal and accessory muscles and then the diaphragm (Chaudhuri and Behan, 2009). Bulbar (oropharyngeal) muscle dysfunction may be the predominant feature in some patients (Putman and Wise, 1996). In MuSK-MG, bulbar weakness always precedes respiratory failure (Chaudhuri and Behan, 2009). The central ventilatory drive in myasthenics usually remains intact during crisis, even when the minute ventilation response to $\mathrm{CO}_{2}$ is poor (Rabinstein and Wijdicks, 2003). 
Clinically, ptosis, ophthalmoparesis, and facial and bulbar weakness are common, in addition to generalized weakness. At the bedside, recruitment of accessory muscles indicates significant inspiratory muscle weakness, and a weak cough or difficulty in counting to 20 in a single breath signifies weakness of the expiratory muscles (Juel, 2004). Patient anxiety, accompanied by tachycardia and tachypnea, may be the first sign of air hunger (Table 1). Signs of bulbar weakness include dysphagia, nasal regurgitation, a nasal quality to speech, staccato speech, jaw weakness (jaw closure weaker than jaw opening), bifacial paresis, and tongue weakness (Garcia-Pachon et al., 1996; Rabinstein and Wijdicks, 2003). The most important dysfunction of the upper airway leading to respiratory failure is laryngeal muscle weakness causing abnormal adduction of the vocal cords during inspiration and even paralysis (Friedman and Goffin, 1966). Respiratory failure may develop due to aspiration, catastrophic airway compromise, or increased work of already fatigued respiratory muscles against a closed airway (Putman and Wand, 1996).

One particular danger in myasthenic crisis is that the generalized weakness can mask the usual signs of respiratory distress. In addition, weak respiratory muscles may suddenly fatigue, producing precipitous respiratory collapse. Some patients may present with respiratory insufficiency out of proportion to limb or bulbar weakness. In rare cases of myasthenic crisis, ventilatory failure is the only clinically overt manifestation (Mier et al., 1990; Dushay et al., 1990). Therefore, signs of myasthenic crisis should be sought in all patients with MG, even when they do not complain of weakness.

\begin{tabular}{|l|}
\hline Abdominal muscle paradox \\
Accessory muscle use \\
Cough after swallowing \\
Difficulty in clearing secretions \\
Dysphagia \\
Hypophonia \\
Inability to raise the head due to neck muscle weakness \\
Forehead sweating \\
Jaw weakness (jaw closure weaker than jaw opening) \\
Nasal regurgitation \\
Orthopnea \\
Pausing during speech to take a breath \\
Rapid shallow breathing \\
Staccato speech or a nasal quality to speech \\
Single breath count of < 15 \\
Stridor \\
Tachypnea \\
Tongue weakness \\
Weak cough \\
Wet, gurgling voice
\end{tabular}

Table 1. Warning symptoms and signs of impending respiratory failure in myasthenic crisis. (Rabinstein, 2003; Bedlack and Sanders, 2002; Juel, 2004) 


\section{Assessment of respiratory muscle strength and bulbar function}

\subsection{Assessment of vital capacity (VC)}

The VC reflects the mechanical function of both inspiratory and expiratory respiratory muscles and can be performed at the bedside to assess the patient's trend (Juel, 2004; Rabinstein and Wijdicks, 2003). The patient is instructed to take a deep breath in and then to exhale maximally into a spirometer. Some experts recommend assessing both supine and sitting VC, as diaphragmatic weakness is more apparent on the supine measurement. Supine VC has been shown to be an earlier marker of detect diaphragm dysfunction.

\subsection{Assessment of inspiratory muscle function}

\subsubsection{Maximal inspiratory pressure (PImax)}

The static PImax measured during a maximal inspiratory effort that is sustained for $\geq 1 \mathrm{~s}$ against an occluded airway is the most widely used parameter for assessing inspiratory muscle strength, Although the early literature reported that PImax testing should be performed from residual volume (RV), more recent work has shown that it is reasonable to simplify the procedure by measuring this pressure from the functional residual capacity (FRC) (Windisch et al., 2004). The normal range of PImax values is wide and some patients may have difficulties in performing the procedure, particularly those with bulbar dysfunction.

\subsubsection{Sniff nasal inspiratory pressure (SNIP)}

Alternative techniques have been developed over the last few years to assess the inspiratory function. One of the most promising is determination of SNIP, which consists in the measurement of pressure through an occluded nostril during sniffs, performed through the contralateral nostril (Soliman et al., 2005). The testing of SNIP should be performed from FRC. It has been shown to be a good physiological marker of inspiratory muscle strength (MartínezLlorens et al., 2011). SNIP maneuver is easier to perform than PImax maneuver, and it is as reproducible as Pimax, However SNIP may underestimate esophageal pressure swing in subjects with nasal obstruction and severe neuromuscular weakness. Multiple tests to assess respiratory muscle strength are required to exclude weakness in symptomatic patients (Steier et al, 2007; Hart et al., 2003). Because, of the limit of agreement between SNIP and PImax, these two methods are not interchangeable but complementary (Prigent et al., 2004).

\subsubsection{Sensitivity of volume vs. pressure measures}

It remains controversial whether volume or pressure measurements are more sensitive in the assessment of respiratory muscle function. The theoretical curvilinear relation between volume and pressure implies that, in the case of mild respiratory muscle weakness, VC is less sensitive than PImax, and, in more advanced disease, marked reduction in VC can occur with relatively small changes in maximum pressures. One previous study showed that inspiratory and expiratory forces were more sensitive than VC in evaluating muscle strength in MG (Mier-Jedrzejowicz et al., 1988). However, a recent study found that PImax was not more sensitive than VC for early detection of respiratory muscle failure in these patients (Prigent et al., 2011). Since neither measurement has been shown to be superior, the two parameters are usually analyzed in combination. 


\subsection{Assessment of expiratory muscle function}

\subsubsection{Maximal expiratory pressure (PEmax)}

The strength of the expiratory muscles can be assessed by the maximal expiratory pressure (PEmax) (Rabinstein et al., 2003), which can be measured at the mouth in an analogous fashion to PImax during a forced expiration (from total lung capacity maneuver). It represents the integration of exhalation muscle strength and sufficient cough flows have to be generated by expiratory muscles to allow airway clearance. In a study of neuromuscular diseases (Perez, 2006), PEmax below $45 \mathrm{~cm} \mathrm{H}_{2} \mathrm{O}$ was associated with compromised cough efficiency, and PEmax $<40 \mathrm{~cm} \mathrm{H}_{2} \mathrm{O}$ may indicate crisis (Lacomis, 2005). It is important to prevent the subject from using buccal manoeuvres to increase the mouth pressure. As with PImax, PEmax values have a wide normal range.

\subsubsection{Peak cough flow}

Another simple and commonly used test of expiratory muscles is the peak cough flow, which can be performed using a standard peak flow meter attached to a face mask and usually requires little or no coaching to produce acceptable technique. Cough assessment is an inexact science, however, because of the lack of accurate measures. A peak cough flow value of $<270 \mathrm{~L} / \mathrm{min}$ has been proposed as a threshold for cough inadequacy, but this has never been validated. Patients with a peak cough flow $<180 \mathrm{~L} / \mathrm{min}$ are unable to independently clear secretions (Bach, 1995). In myasthenics, peak cough flow has been shown to be useful in monitoring expiratory muscle strength (Suárez et al., 2002; Wilson et al., 2005). It must be realized that although this test indicates expiratory muscle performance the pressure and force generated depends on lung volumes and coordinated bulbar function to rapidly open and close the glottis during cough pressure generation and release. Therefore, values obtained will be reduced in patients with inspiratory muscle weakness due to inability to perform deep inspiration prior to cough initiation (Polkey et al., 1998).

\subsection{Assessment of bulbar function}

Although critical for management decisions, reliable clinical assessment of bulbar function with MG is often difficult (Hudspeth et al., 2006). As it is well established, the involvement of upper airway muscles in neuromuscular diseases can produce abnormalities of the maximum flow-volume loop (MFVL) in the form of upper airway obstruction and/or flow oscillations (Putman and Wise, 1996). Upper airway obstruction is much more common in patients with MG than previously recognized. In one study, 7 of the $12 \mathrm{MG}$ patients examined disclosed a pattern of extrathoracic upper airway obstruction (Putman and Wise, 1996). In addition, a crude but effective bedside test can be performed by asking the patient to sip water and then observing for coughing or choking. This "slurp" test has been shown to be valuable for identifying serious compromise of bulbar function and for monitoring and guiding therapy in pediatric patients with MG (Hudspeth et al., 2006).

\section{Initial respiratory care in the ICU}

The respiratory management of myasthenic crisis does not differ between patients with AChR-MG, MuSK-MG and seronegative patients (Chaudhuri and Behan, 2009). 


\subsection{Initial evaluation and airway management}

Patients with crisis should be referred for intensive care. The initial step is stabilization of the airway. The airway should be opened by suctioning secretions after positioning the jaw and tongue. High-flow oxygen should be administered and oxygen saturation be monitored by pulse oximetry continuously. If respirations remain inadequate, patients can be ventilated by a bag-valve mask while preparing to intubate. In the patient without an intact gag reflex, an oral airway may be placed to prevent aspiration. Patients should always be asked about recent difficulty with swallowing, choking, coughing after eating, and nasal regurgitation. If the patient's history or the "slurp" test is suggestive of dysphagia, oral intake is eliminated.

Once the airway is secured, investigation into the cause of the exacerbation of MG may proceed. Any medication suspected of precipitating crisis should be discontinued (Keesey, 2004). Chest radiography is important in detecting pneumonia. Appropriate broad-spectrum antibiotics are indicated for sepsis and pneumonia. It is important to consider that fluoroquinolones and aminoglycosides may adversely affect muscle function in these patients, and these antibiotics should be avoided if possible.

Prompt recognition of impending respiratory paralysis is the key to successful management. The classical signs of respiratory distress, however, often occur too late in these patients to serve as guidelines for management. Respiratory assistance should be provided if $\mathrm{VC}$ is < $15-20 \mathrm{~mL} / \mathrm{kg}$, the tidal volume $<5-6 \mathrm{~mL} / \mathrm{kg}$, or if $\mathrm{PaO}_{2}$ drops to $<85 \mathrm{~mm} \mathrm{Hg}$ and $\mathrm{PaCO}_{2}$ increases to $>45 \mathrm{~mm} \mathrm{Hg}$. Oxygen saturation and ABG abnormalities, however, are generally not considered ideal for use in making intubation decisions because these values change late in the decompensation cycle (Juel, 2004; Rabinstein and Wijdicks, 2003; Bird and Teener, 2001).

\subsection{Bronchodilator therapy}

One recent study found that patients with MG had significantly lower $\mathrm{FEV}_{1} / \mathrm{FVC}$ ratio than controls. This was more marked in patients on acetylcholine esterase inhibitors (Elsais et al., 2010). In myasthenic crisis, bronchodilators may be useful in maintaining airway patency and overcoming bronchospasm. For myasthenics with concomitant chronic obstructive pulmonary disease (COPD), inhaled ipratropium bromide may be the bronchodilator drug of choice because it is safe and can decreased bronchial secretions which may limit the use of cholinesterase inhibitors (Szathmáry et al., 1981; Liggett et al., 1988). A recent pilot study also suggests that terbutaline, a $\beta_{2}$ adrenergic agonist, may be an effective adjunct therapy in these patients, although confirmation with larger trials will be required (Soliven et al., 2011).

\subsection{Indications and predictors for endotracheal intubation}

Two-thirds to $90 \%$ of patients with myasthenic crisis require intubation and mechanical ventilation (Thomas et al., 1997; O'Riordan et al., 1998). Over 20\% of patients require intubation during evaluation in the emergency department, and almost $60 \%$ are intubated after admission to an ICU (Thomas et al., 1997). The absolute indications for intubation may include cardiac or respiratory arrest, impaired consciousness shock, life-threatening arrhythmias, severe blood-gas alterations, and bulbar dysfunction with confirmed aspiration. Much more difficult is the decision to intubate when such strict criteria are not met. 
In most patients, repeated measurements of VC and PImax help determine the need for and timing of elective intubation (Ahmed et al., 2005; Rabinstein and Wijdicks, 2003). These indices can be measured as often as every two hours, but typically every four hours. The standard 20/30/40 rule (VC $<20 \mathrm{~mL} / \mathrm{kg}$; PImax $<\_30 \mathrm{~cm} \mathrm{H}_{2} \mathrm{O}$ and PEmax $<40 \mathrm{~cm} \mathrm{H}_{2} \mathrm{O}$ ) is probably the most helpful guide to decide when intubation (Chaudhuri and Behan, 2009). However, these threshold values have not been established through prospective studies, nor do they allow for individual differences in size, sex, and age. In addition, muscle weakness in myasthenic crisis often fluctuates, and patients can develop apnea very suddenly, or may precipitously fatigue with the rapid development of respiratory failure before a downward trend in these parameters is noted. Facial weakness can also lead to inaccurate measurements of these indices due to inability to make a good seal with the mask (Lacomis, 2005). In a retrospective review, repeated measurement of VC did not predict the need for intubation and mechanical ventilation in these patients (Rieder et al., 1995). Thus, these respiratory parameters should always be interpreted in the context of the clinical symptoms and signs, as well as the trend in these measures. Regardless of respiratory function indices, the need for mechanical ventilation is a sufficient criterion to define myasthenic crisis (Ahmed et al., 2005). With close monitoring of the patient's condition, endotracheal intubation can often be performed electively rather than as an emergent response to precipitous respiratory collapse (Juel, 2004; Rabinstein and Wijdicks, 2003; Bird and Teener, 2001).

\subsection{Procedures for endotracheal intubation}

Should the need for emergent intubation develop, rapid sequence intubation should be modified because neuromuscular blocking agents (paralytics) should be used with caution when intubating these patients. Depolarizing agents (for example, succinylcholine) are less potent in myasthenics because fewer functional post-synaptic anti-AChR are available. This decrease in receptors also results in a decrease in the safety margin or remaining $\mathrm{AChR}$ available for neuromuscular transmission. Nondepolarizing agents (fornexample, vecuronium) have increased potency, and reduced doses are required for paralysis. (Baraka, 1992). A rapid-onset nondepolarizing agent (ie, rocuronium, vecuronium) is the preferred paralytic agent for these patients. Although nondepolarizing agents delay the onset of paralysis, compared with succinylcholine, these medications do not result in unwanted prolonged paralysis. Following paralysis, intubation is accomplished as usual. A soft, lowpressure cuff is recommended. After intubation, chest radiography should be taken to confirm the position of the artificial airway.

\subsection{Modification of pharmacotherapy after intubation}

After intubation, cholinesterase inhibitor therapy is usually temporarily withdrawn to avoid the excess secretions that may complicate pulmonary management. In addition, continued use of these medications confounds the assessment of other treatment modalities and can increase muscle weakness if used in excess (Ahmed et al., 2005). These medications do not alter the course of the crisis and offer solely symptomatic relief of MG (Juel, 2004). After patients have shown definitive improvement in muscle strength, usually several days after the initiation of intravenous immunoglobulin (IVIg) or plasma exchange, acetylcholinesterase inhibitors, typically oral pyridostigmine, can be reintroduced after or 
just prior to extubation (Juel, 2004; Ahmed et al., 2005). Oral pyridostigmine is preferred, but it may be given intravenously. One milligram of intravenous pyridstigmine is equal to 30 $\mathrm{mg}$ of oral pyridostigmine. Patients should be started on a low dose of the medication that is titrated to symptomatic relief (Ahmed et al., 2005). Continuous intravenous infusion of pyridostigmine as treatment for myasthenic crisis may have efficacy similar to that of plasma exchange, but it is associated with an increased risk of life-threatening cardiac arrhythmia (Wendell and Levine, 2011). Unless contraindicated, all patients should be treated with low molecular weight heparin to prevent deep vein thrombosis and pulmonary embolism (Chaudhuri and Behan, 2009).

\section{Ventilatory management strategies}

\subsection{Ventilator settings}

Once intubated, patients should be placed in a semi-recumbent position with the head of the bed at approximately 30 degrees. Large tidal volumes of $10 \mathrm{~mL} / \mathrm{kg}$, along with pressure support of 5 to $15 \mathrm{~cm} \mathrm{H}_{2} \mathrm{O}$ and positive end-expiratory pressure (PEEP) of 5 to $15 \mathrm{~cm} \mathrm{H}_{2} \mathrm{O}$, are encouraged to limit atelectasis, provided peak airway pressures can be maintained below 40 $\mathrm{cm} \mathrm{H}_{2} \mathrm{O}$ (Kirmani et al., 2004; Varelas et al., 2002). The degree of support required is patientdependent and should be adjusted based on ABG analysis. In patients with chronic carbon dioxide retention (suggested by elevated serum bicarbonate levels), $\mathrm{PaCO}_{2}$ should be kept above $45 \mathrm{~mm} \mathrm{Hg}$ to avoid alkalosis and bicarbonate wasting, which make weaning more difficult. Frequent checks of cuff pressure, tube placement, and blood gases are recommended.

\subsection{Chest physiotherapy and airway clearance}

Meticulous attention to pulmonary toilet is required because of an ineffective cough mechanism. Aggressive chest physiotherapy and airway clearance should be implemented (Varelas et al., 2002). Inspired gas humidity should be around $80 \%$ at $37^{\circ} \mathrm{C}$. Various modalities, include percussion, vibration, and postural drainage. should be carried out to loosen and remove bronchial secretions and to achieve better aeration of collapsed areas of the lung (Brooks-Brunn, 1995; Lewis, 1980; Selsby and Jones, 1990). Regular suctioning serves to not only remove excess oropharyngeal and tracheal secretions but also to stimulate coughing (Varelas et al., 2002). Patients with a cough PEF $<180 \mathrm{~L} / \mathrm{min}$ can augment cough response with manual physiotherapy and using insufflation-exsufflation devices (Chatwin et al., 2003) and this augmented cough level is associated with improved prognosis independent of VC or breathing pattern (Bach, 1995).

If atelectasis is severe and does not respond to routine measures, therapeutic fiberoptic bronchoscopy can be performed to promote airway toilet. Frequent body repositioning is effective in enhancing oxygen transport by changing the ventilation and perfusion of the lungs through gravitational effects and by enhancing mobilization of secretions. Early mobilization and ambulation as tolerated is also encouraged.

\subsection{Nutrition and other issues during mechanical ventilation}

Adequate nutrition is important to avoid a negative energy balance and worsening of muscle strength (Kirmani et al., 2004). All patients received adequate nutritional support (25-35 calories per kilogram) via enteral route whenever possible. In patients with 
hypercarbia and difficulty weaning from the ventilator, low carbohydrate feeds are the preferred solution (Varelas et al., 2002).

In addition to the aforementioned measures, abnormal laboratory values that could affect muscle strength should also be corrected. Potassium, magnesium, and phosphate depletion can all exacerbate myasthenic crisis and should be repleted. Anemia can also increase weakness, and several experts recommend transfusions when hematocrit values are under 30\% (Kirmani et al., 2004; Ahmed et al., 2005). Prophylaxis for deep vein thromboses, such as administration of subcutaneous heparin sodium or use of pneumatic compression boots, is recommended.

\section{Weaning from mechanical ventilation and risks for extubation failure}

\subsection{Disadvantages of prolonged intubation}

Prolonged intubation in myasthenic patients may lead to several complications such as atelectasis, anemia, urinary tract infection, congestive heart failure (Ahmed et al., 2005), and ventilator-associated pneumonia (VAP) (Wu et al., 2008). Patients with a prolonged intubation were hospitalized 3 times longer and were less likely to be functionally independent upon discharge (Thomas et al., 1997). In one series, 3 independent risk factors for prolonged intubation ( $>14$ days) were identified: age $>50$ years, peak $\mathrm{VC}<25 \mathrm{~mL} / \mathrm{kg}$ on post-intubation days 1 to 6 , and a serum bicarbonate $\geq 30 \mathrm{mmol} / \mathrm{L}$ (Thomas et al., 1997). All of the patients with no risk factors were intubated for less than 2 weeks, whereas $88 \%$ of the patients with all 3 risk factors had prolonged intubation.

\subsection{Evaluation for weaning in myasthenia crisis}

Deciding on when to stop mechanical ventilation in myasthenic crisis is a challenge for the intensivists, because the usual criteria don't necessarily apply. Evaluation for weaning should begin when patients are objectively getting stronger on examination. In addition, improvement in the strength of neck flexors and other adjunct muscles is usually associated with improvement in bulbar and respiratory muscle strength and can be a useful tool for assessing clinical improvement (Meriggioli, 2009). Patients should be transitioned to a spontaneous mode of ventilation (eg, pressure support ventilation) in which all breaths are patient initiated. Pressure support can then gradually be decreased to minimal settings, usually 5 to $8 \mathrm{~cm} \mathrm{H}_{2} \mathrm{O}$. If results of assessments indicate muscle fatigue, the previous level of ventilator support should be reinstituted (Kirmani et al., 2004). In patients with chronic $\mathrm{CO}_{2}$ retention, $\mathrm{PaCO}_{2}$ should be kept above $45 \mathrm{~mm} \mathrm{Hg}$ to avoid alkalosis and bicarbonate wasting, which may make weaning more difficult.

Current recommendations about managing the weaning process emphasize the daily determination of simple criteria (Fly et al., 1996; Fly et al., 1999). Some criteria are generally used: 1) Satisfactory oxygenation, for instance $\mathrm{PaO}_{2} / \mathrm{FIO}_{2} \geq 200 \mathrm{~mm} \mathrm{Hg}$ with PEEP $\leq \_5 \mathrm{~cm}$ $\mathrm{H}_{2} \mathrm{O}$; 2) A criterion for hemodynamic stability, e.g., no continuous vasopressor infusion; 3) Patient awake or easily aroused and sedation stopped; and 4) Patient able to cough effectively.

\subsection{Spontaneous breathing trial (SBT)}

Readiness for extubation from a respiratory standpoint is largely judged on the basis of patient performance during an SBT. Two main methods are used: T-piece and a low level of 
PSV, with a duration ranging from $30 \mathrm{~min}$ to 2 hours (Esteban et al., 1997). It should always begin early in the day. During this period, patient anxiety, pulse and respiratory rates, and tidal volume again are frequently documented. There are no good clinical criteria for when and how to try extubation safely, thus avoiding the need for reintubation. Fluctuating weakness and pulmonary complications often confound the decision to extubate (Seneviratne et al., 2008). Patients are typically extubated if VC and PImax are $\geq 15 \mathrm{~mL} / \mathrm{kg}$ and $\leq_{-}-20 \mathrm{~cm} \mathrm{H} \mathrm{H}_{2} \mathrm{O}$, respectively, and tidal volume $\geq 5 \mathrm{~mL} / \mathrm{kg}$ (Kirmani et al., 2004; Meriggioli, 2009). In our study, a PEmax of $>40 \mathrm{~cm} \mathrm{H}_{2} \mathrm{O}$ was a good predictor of extubation success in these patients (Wu et al., 2009). If the patient complains of fatigue or shortness of breath, extubation should not be performed even if the criteria of these indices are met and blood gases are normal (Berrouschot et al., 1997; Gracey et al., 1983; Kelly, 1991). Our experience also indicates that the rapid shallow breathing index (breathing frequency divided by tidal volume) is a poor predictor for extubation outcome in patients with neuromuscular diseases (Kuo et al., 1996; Wu et al, 2009).

\subsection{Potential utility of new modes of mechanical ventilation}

Some new modes of mechanical ventilation, which are aimed at unloading the inspiratory muscles and preventing patient-ventilator dyssynchrony, may be useful in neuromuscular patients with difficult weaning. These modes include proportional assist ventilation (PAV), adaptive support ventilation (ASV), and neurally-adjusted ventilatory assist (NAVA). However, there is still no evidence from randomized controlled trials to support or refute the use of these modes in myasthenic crisis. Automatic tube compensation (ATC) is a special mode of ventilatory support which delivers the amount of pressure necessary to overcome the resistive load imposed by the endotracheal tube for the flow measured at the time (Fabry et al., 1994). This mode therefore unloads the flow-resistive properties of the artificial airway and can increase the probability of successful extubation. One recent report indicates that the addition of ATC to a standard PSV-based weaning protocol significantly shortened time needed to wean patients with severe neuromuscular paralysis (Agarwal et al., 2009). It is possible that ATC will be a useful weaning mode in myasthenic crisis, especially for patients who are intubated with a small-size endotrachel tube.

\subsection{Respiratory care after extubation}

To enhance mucous clearance and prevent sputum impaction after extubation, it is reasonable to consider airway clearance techniques, such as positive expiratory pressure, autogenic drainage, and active cycle of breathing techniques in these patients (Hardy and Anderson, 1996). The addition of mechanical insufflation/exsufflation may shorten airwayclearance sessions in neuromuscular patients with chest infection (Chatwin and Simonds, 2009). The intrapulmonary percussive ventilator and high-frequency chest wall oscillator with vests may show growing promise in this area (Toussaint et al., 2003). However, these modalities have not been specifically in myasthenics. Externally applied pressure, such as with the In-Exsufflator or the cyclically inflated pneumatic belt, can augment the patient's own efforts and is sometimes helpful. Normalizing the VC and FRC typically helps to improve the ability to cough and clear secretions. Sputum mobilization can be facilitated with the Flutter valve therapy without the assistance of another caregiver, as long as the patient has the motivation. Incentive spirometry can also be used to reduce the risk of 
atelectasis and re-intubation (American Association for Respiratory Care, 1991), but its usefulness in myasthenic crisis patients is not clear.

The risk of spontaneous relapse of myasthenic crisis is low in early-onset disease. A third of late onset severe disease, especially in MuSK-MG, may experience recurrent crisis (Chaudhuri and Behan, 2009). Therefore, close observation for 72 hours in the ICU is recommended for each patients after extubation. The duration of observation may have to be longer for less stable patients.

\subsection{Extubation outcome and the risk of extubation failure}

The rate of extubation failure in medical patients undergoing invasive mechanical ventilation ranges from 3\% to 19\% (Epstein et al., 1997; Mador, 1998). This percentage seems to be much higher in neuromuscular diseases. One study published in 1997 reported that only half of patients were extubated within two weeks after intubation (Thomas et al., 1997). More recent studies indicate that extubation failure still occurs in more than $25 \%$ of these patients (Rabinstein and Mueller-Kronast, 2005; Seneviratne et al., 2008). Reintubaton is a significant event because these patients have significantly longer ICU and hospital stays (Rabinstein and Mueller-Kronast, 2005). Extubation failure is also associated with a higher incidence of ventilator-associated pneumonia (VAP) (Wu et al., 2009). Atelectasis is the most important risk factor for extubation failure in myasthenic crisis. Two retrospective studies found atelectasis in all patients requiring reintubation (Rabinstein and Mueller-Kronast, 2005; Seneviratne et al., 2008). Other factors identified include older age, pneumonia, acidosis, decreased VC, and need for noninvasive ventilatory support are predictors of reintubation (Rabinstein and Mueller-Kronast, 2005; Seneviratne et al., 2008; Wu et al., 2008).

Cough power is a strong predictor for extubation success in neuromusclar diseases. Bach and Saporito have reported that all patients with a cough PEF $<160 \mathrm{~L} / \mathrm{min}$ had to be reintubated within 48 hours, the most likely reason being airway congestion because of the lack of adequate cough assistance (Bach and Saporito, 1996). In addition, patients who had passed SBT but presented cough PEF of $60 \mathrm{~L} / \mathrm{min}$ or less were nearly 5 times more likely to fail extubation compared with those with cough PEF higher than $60 \mathrm{~L} / \mathrm{min}$ (Salam et al., 2004). In myasthenics, our data indicate that extubation failure is most commonly associated with a weak cough and inadequate airway clearance, and Pemax is useful in predicting cough strength after extubation (Wu et al., 2009).

\subsection{Tracheostomy}

Tracheostomy is generally not needed in myasthenic crisis because the duration of intubation is often less than 2 weeks. Tracheostomy placement ranges from 14 to $40 \%$ (Thomas et al., 1997; Rabinstein and Mueller-Kronast, 2005). In our retrospective analysis of 41 episodes, tracheostomy was performed in four (9.8 \%) patients after being ventilated for a median duration of 26 days (range: 20 to 30 days) (Wu et al., 2009). All these four patients were finally liberated from mechanical ventilation (Wu et al., 2009). One rare condition in myasthenic crisis that often requires tracheostomy is severe upper airway obstruction due to bilateral vocal cord paralysis. Approximately 11 such cases have been been reported in the literature and tracheotomy was required in the majority of these patients (Hanson et al., 1996). 


\section{Role of non-invasive positive pressure ventilation (NIPPV)}

\subsection{Advantages of NIPPV in neuromuscular diseases}

The application of NIPPV can augment airflow and prevents airway collapse and maintaining gas exchange by offering positive airway pressure both in the inhalation and exhalation phases of respiration. It has been applied successfully in slowly progressive neuromuscular diseases, such as Duchenne muscular dystrophy or amyotrophic lateral sclerosis (Seneviratne et al., 2008). NIPPV should be started at low pressures initially and then inspiratory pressure is gradually increased while monitoring tolerance, symptoms, and gas exchange. NIPPV is also increasingly being used to prevent extubation failure in these patients. A recent prospective study suggests that application of NIPPV, combined with assisted coughing after extubation, averts the need for reintubation or tracheostomy in patients with neuromuscular diseases and shortening their stay in the ICU (Vianello et al., 2011). It should be included in the routine approach to these patients at high risk for postextubation respiratory failure.

\subsection{Contraindications and disadvantages of NIPPV}

Contraindications remain to the application of NIPPV in the acute setting, including respiratory arrest, severe inability to protect the airway, uncontrollable airway secretions despite use of noninvasive aids, life-threatening hypoxemia, severely impaired mental status or agitation, hemodynamic or electrocardiographic instability, and bowel obstruction (Hill et al., 2011). In patients with bulbar involvement, air blowing through a mask can lead to aspirated secretions and great care must be taken when using this modality (Wu et al., 2009). Current evidence suggests that NIPPV should be used judiciously, if at all, in patients with postextubation respiratory failure (Aqarwal et al., 2007).

\subsection{Application of NIPPV in myasthenic crisis}

The definition of myasthenic crisis was introduced before NIPPV was widely applied to patients with hypercapnic respiratory failure. One common dilemma is whether to do immediate intubation in a patient presenting with warning signs of imminent respiratory failure or to start with NIPPV support. There are studies that lend some credence to its use in selected patients with myasthenic crisis. In 2002, Rabinstein et al. first reported their experience of using NIPPV in these patients. In their case series, NIPPV was well tolerated and the length of hospital stay was significantly reduced compared to those who were intubated (mean $7 \pm 5$ days vs. $23 \pm 16$ days; $p=0.03$ ). Most failures $(75 \%)$ occurred within the first 24 hours of NIPPV use (Rabinstein et al., 2002). Several subsequent reports suggest that NIPPV may be useful in preventing intubation as well as reintubation in these patients (Rabinstein and Wijdicks, 2002; Rabinstein and Wijdicks, 2003; Seneviratne et al., 2008; Wu et al., 2009). In 60 episodes of crisis in 52 patients, Seneviratne et al. reported that NIPPV was the initial method of ventilatory support in 24 episodes, and intubation was avoided in 14 of these episodes (Seneviratne et al., 2008). Patients treated initially with NIPPV require ventilatory support for a median of 4 days versus 9 days in those patients initially intubated. A recent report also indicate that patients undergoing NIPPV spend one-third less time in the ICU and in the hospital, and the predictor of NIPPV failure was a $\mathrm{PaCO}_{2}$ level exceeding $45 \mathrm{~mm} \mathrm{Hg}$ on NIPPV initiation (Seneviratne et al., 2008). One retrospective cohort study 
found that NIPPV was never aborted because of excessive respiratory secretions in myasthenics, and there was no difference in pulmonary complications between those supported with NIPPV and those supported with endotracheal intubation mechanical ventilation (Seneviratne et al., 2008). In our study, independent predictors of NIPPV success were a serum bicarbonate $<30 \mathrm{mmol} / \mathrm{L}$ and an APACHE (Acute Physiological And Chronic Health Evaluation) II score $<6$ (Wu et al., 2009). Our experience also suggests that intubation should be performed if the patient on NIPPV has continued or worsening shortness of breath, tachypnea, or hypercapniea.

\subsection{NIPPV to prevent reintubation}

Early application of NIPPV after extubation can reduce the risk of respiratory failure and lowered mortality in hypercapnic patients with chronic respiratory disorders (Ferrer et al., 2009). Use of NIPPV to avoid reintubation in myasthenic crisis is well established but relatively uncommon practice (Saeed and Patel, 2011). Some studies reported that NIPPV prevented reintubation in 70\% of patients (Wu et al., 2009; Rabinstein and Wijdicks, 2002). Randomized controlled trials on the technique should be conducted before concluding the overall beneficial outcome.

\section{Role of negative pressure ventilation}

In recent years, the development of more portable and flexible devices has resulted in the renewed interest in the use of negative pressure ventilation to minimise the complications associated with positive pressure ventilation. Many of these devices can make the patients more comfortable with the ability to talk, eat and breathe freely around the mandatory negative pressure breaths. For example, the latest generation of biphasic cuirass ventilators are versatile and the duration and pressure can be altered in both the inspiratory and expiratory phases, which can promote the removal of secretions by external high-frequency oscillation as well as expiratory (cough) assistance (Linton, 2005; Koto et al., 2009). For myasthenic patients with relatively normal pulmonary compliance and airway resistance, it makes good sense to try cuirass ventilation to achieve earlier extubation. It should also reduce the incidence of VAP and laryngeal injury. Patients can then be moved to a step down or intermediate care facility, or even home, until muscle strength recovers.

\section{Outcome and prognosis}

\subsection{Mortality}

Patients in myasthenic crisis have an excellent outcome if respiratory support can be provided adequately and in time. The prognosis of myasthenic crisis has substantially improved. During the early 1960s, respiratory care of these patients was transitioned from negative external pressure ventilation to positive pressure ventilation in an ICU. The mortality rate during hospitalization has decreased from $42 \%$ in the early 1960 s to $6 \%$ by the late 1970s, between $3 \%$ and $10 \%$ in the early 1980s, and less than $3 \%$ in the 1990 s. The median age at death also increased (Cohen and Younger, 1981). The rate of mortality has continued to decline after 1990, presumably because of improvements in respiratory care and availability of treatment options including IVIG and plasma exchange (Alshekhlee et al., 2009). Based on the data in the US from 2000 through 2005, the overall in-hospital mortality 
rate in patients with MG was 2.2\%, being higher in patients with crisis (4.47\%) (Alshekhlee et al., 2009). Older age and respiratory failure were the predictors of death, with adjusted odds ratios of 9.28 and 3.58, respectively (Alshekhlee et al., 2009). In that cohort, significantly higher occurrence of cardiac complications, sepsis, and deep vein thrombosis was observed among patients with crisis; however, none of these complications were independent predictors of death (Alshekhlee et al., 2009).

\subsection{Duration of mechanical ventilation and prognosis}

Prior reports indicated a median duration of intubation of 13 days or ICU stay of 14 days (Murthy et al., 2005; Tether, 1955). A recent study noted a shorter median length of hospital stay of 6 days. However, this duration was 17 days for myasthenic patients who underwent endotracheal intubation (Alshekhlee et al., 2009). Duration of intubation is an important predictor of functional outcome after crisis. About $25 \%$ of patients are extubated on hospital day $7,50 \%$ by hospital day 13 , and $75 \%$ by hospital day 31 . Eighteen percent of patients will require discharge to a rehabilitation center (Alshekhlee et al., 2009). In a retrospective study of 73 episodes of crisis, risk factors for prolonged intubation include patient age over 50 years, preintubation serum bicarbonate levels above $30 \mathrm{mg} / \mathrm{dL}$, and highest $\mathrm{VC}$ of less than $25 \mathrm{~mL} / \mathrm{kg}$ during the first week of intubation (Thomas et al., 1997). The risk of prolonged intubation (i.e., $>2$ weeks) was $0 \%$ in patients with none of these risk factors, $20 \%$ in those with one risk factor, $50 \%$ in those with two risk factors, and $90 \%$ in those with three risk factors (Thomas et al., 1997). In another study, 77\% of patients intubated for more than 2 weeks had functional dependence at discharge compared with $36 \%$ of patients intubated for less than 2 weeks.

1. Referred for intensive care.

2. Initial step is stabilization of the airway

3. Adequate oxygenation and ventilation.

4. Airway protection if bulbar dysfunction to prevent aspiration.

5. NIPPV if no contraindications.

6. Monitor vital signs and repeated measurements of muscle strength (VC, PImax, SNIP, PEmax, peak cough flow...).

7. 20/30/40 rule to guide intubation ( symptoms and signs more important).

8. Elective rather than emergency intubation.

9. Recommended initial ventilator settings: tidal volume $10 \mathrm{~mL} / \mathrm{kg}$, PS 5-15 $\mathrm{cm} \mathrm{H}_{2} \mathrm{O}$ and PEEP 5-15 $\mathrm{cm} \mathrm{H} \mathrm{H}_{2} \mathrm{O}$, peak airway pressure $<40 \mathrm{~cm} \mathrm{H}_{2} \mathrm{O}$

10. Aggressive chest physiotherapy and airway clearance.

11. Evaluation for weaning when muscular strength is objectively improved.

12. Identify readiness for extubation by spontaneous breathing trials (T-piece, PS, automatic tube compensation...).

13. Close monitoring and airway toilet after extubation. Tracheostomy is generally not needed.

Table 2. Summary of respiratory care for myasthenic crisis 


\section{Conclusion}

Myasthenic crisis is a rare but potentially life-threatening medical emergency and the diagnosis should be clinically suspected. The muscles involved and the degree of weakness vary from patient to patient, and respiratory care of these patients presents a challenge for the critical care practioners. Although no single factor determines the need for respiratory support, all patients with questionable respiratory status should be admitted to the ICU. Certain tests of respiratory muscle strength may help to identify impending respiratory failure and allow elective rather than emergent intubation. When treated aggressively adequately, patients generally have good outcomes in current practice. Successful management of patients not only involves the pharmacological aspect but a major part is mechanical ventilation. There is a clear need for formal randomized controlled trial of NIPPV in these patients as it seems to be a promising approach. Patient selection and close monitoring, however, remain important for successful application of NIPPV in myasthenic crisis. Because management of crisis includes treatment of the underlying MG, it is apparent that there is an urgent need for cooperation between specialist chest physicians, neurologists and respiratory therapists to optimize the care of this particular population of patients.

\section{References}

Aggarwal, AN.; Agarwal, R. \& Gupta, D. (2009). Automatic tube compensation as an adjunct for weaning in patients with severe neuroparalytic snake envenomation requiring mechanical ventilation: a pilot randomized study. Respiratory Care Vol.54, No.12, pp. 1697-1702 ISSN 0020-1324

Ahmed, S.; Kirmani, JF., Janjua, N., Alkawi, A., Khatri, I., Yahia, AM., Souyah, N. \& Qureshi, AI. (2005). An update on myasthenic crisis. Current Treatment Options in Neurology Vol.7, No.2, pp. 129-141, ISSN 1092-8480

Alshekhlee, A.; Miles, JD., Katirji, B., Preston, DC., \& Kaminski, HJ. (2009). Incidence and mortality rates of myasthenia gravis and myasthenic crisis in US hospitals. Neurology Vol.72, No.18, pp. 1548-1554, ISSN 0028-3878

Argov, Z. (2009). Management of myasthenic conditions: nonimmune issues. Current Opinion in Neurology Vol.22, No.5, pp. 493-497, ISSN 1350-7540

Allen, SM.; Hunt, B. \& Green, M. (1985). Fall in vital capacity with posture. British Journal of Diseases of the Chest Vol.79, No.3, pp. 267-271, ISSN 0007-0971

Alshekhlee, A.; Miles, JD., Katirji, B., Preston, DC. \& Kaminski, HJ. (2009). Incidence and mortality rates of myasthenia gravis and myasthenic crisis in US hospitals. Neurology Vol.72, No.18, pp. 1548-1554, ISSN 0028-3878

Bach, JR. (1995). Amyotrophic lateral sclerosis: predictors for prolongation of life by noninvasive respiratory aids. Archives of Physical Medicine and Rehabilitation Vol.76, No.9, pp. 828-832, ISSN 0003-9993

Bach, JR. \& Saporito, LR. (1996). Criteria for extubation and tracheostomy tube removal for patients with ventilatory failure: a different approach to weaning. Chest. Vol.110, No.6, pp. 1566-1571, ISSN 0012-3692

Bae, JS.; Go, SM., \& Kim, BJ. (2006). Clinical predictors of steroid-induced exacerbation in myasthenia gravis. Journal of clinical neuroscience : official journal of the Neurosurgical, Vol.13, No.10, pp. 1006-1010, ISSN 0967-5868 
Brooks-Brunn, JA. (1995). Postoperative atelectasis and pneumonia: Risk factors. American Journal of Critical Care Vol.4, No.5, pp. 340-349, ISSN 1062-3264

Baraka, A. (1992). Anaesthesia and myasthenia gravis. Canadian Iournal of Anaesthesia Vol.39, pp. 476-486, ISSN 0832-610X

Berrouschot, J.; Bauman, I., Kalischewski, P., Sterker, M., \& Schneider, D. (1997). Therapy of myasthenic crisis. Critical Care Medicine Vol.25, No.7, pp. 1228-1235 ISSN 0090-3493

Borel, CO.; Teitelbaum, JS. \& Hanley, DF. (1993). Ventilatory drive and carbon dioxide response in ventilatory failure due to myasthenia gravis and Guillain-Barre syndrome. Critical Care Medicine Vol.21, No.11, pp. 1717-1726, ISSN 0090-3493

Bedlack, RS. \& Sanders, DB. (2002). On the concept of myasthenic crisis. Journal of Clinical Neuromuscular Disease Vol.4, No.1, pp. 40-42 ISSN 1522-0443

Chaudhuri, A. \& Behan, PO. (2009). Myasthenic crisis. QJM Vol.102, No.2, pp. 97-107 ISSN $1460-2725$

Chatwin, M. \& Simonds, AK. (2009). The addition of mechanical insufflation/ exsufflation shortens airway-clearance sessions in neuromuscular patients with chest infection. Respiratory Care Vol.54, No.11, pp. 1473-1479 ISSN 0020-1324

Chatwin, M.; Ross, E., Hart, N., Nickol, AH., Polkey, MI. \& Simonds, AK. (2003). Cough augmentation with mechanical insufflation/exsufflation in patients with neuromuscular weakness. European Respiratory Journal Vol.21 No.3, pp. 502-508 ISSN 0903-1936

Cohen, MS. \& Younger, D. (1981). Aspects of the natural history of myasthenia gravis: crisis and death. Annals of the New York Academy of Sciences Vol.377, pp. 670-677, ISSN 0077-8923

Crescimanno, G.; Marrone, O. \& Vianello, A. (2011). Efficacy and comfort of volumeguaranteed pressure support in patients with chronic ventilatory failure of neuromuscular origin. Respirology Vol.16, No.4, pp. 672-679 ISSN 1323-7799

Dushay, KM., Zibrak, JD. \& Jensen, WA. (1990). Myasthenia gravis presenting as isolated respiratory failure. Chest Vol.97, No.1, pp. 232-234, ISSN 0012-3692

Elsais, A.; Johansen, B. \& Kerty, E. (2010). Airway limitation and exercise intolerance in wellregulated myasthenia gravis patients. Acta Neurologica Scandinavica Supplementum Vol.190, pp. 12-17, ISSN 0065-1427

Ely, EW.; Baker, AM., Dunagan, DP., Burke, HL., Smith, AC., Kelly, PT., Johnson, MM., Browder, RW., Bowton, DL. \& Haponik, EF. (1996). Effect on the duration of mechanical ventilation of identifying patients capable of breathing spontaneously. New England Journal of Medicine Vol.335, No.25, pp. 1864-1869, ISSN 0028-4793

Ely, EW.; Bennett, PA., Bowton, DL., Murphy, SM., Florance, AM. \& Haponik, EF. (1999). Large scale implementation of a respiratory therapist-driven protocol for ventilator weaning. American Journal of Respiratory and Critical Care Medicine Vol.159, No.2, pp. 439-446, ISSN 1073-449X

Epstein, SK.; Ciubotaru, RL. \& Wong, JB. (1997). Effect of failed extubation on the outcome of mechanical ventilation. Chest Vol.112, No.1, pp. 186-192 , ISSN 0012-3692

Esteban, A.; Alía, I., Gordo, F., Fernández, R., Solsona, JF., Vallverdú , I., Macías, S., Allegue, JM., Blanco, J., Carriedo, D., León, M., de la Cal, MA., Taboada, F., Gonzalez de Velasco, J., Palazón, E., Carrizosa, F., Tomás, R., Suarez, J. \& Goldwasser, RS. (1997). Extubation outcome after spontaneous breathing trials with T-tube or pressure support ventilation. The Spanish Lung Failure Collaborative Group. 
American Journal of Respiratory and Ccritical Care Medicine Vol.156, No.2 pt 1, pp. 459-465, ISSN 1073-449X

Fabry, B.; Guttmann, J., Eberhard, L. \& Wolff, G. (1994). Automatic compensation of endotracheal tube resistance in spontaneously breathing patients. Technology and Health Care Vol.1, pp. 281-291, ISSN 0928-7379

Ferrer, M.; Sellarés, J., Valencia, M., Carrillo, A., Gonzalez, G., Badia, JR., Nicolas, JM. \& Torres A. (2009). Noninvasive ventilation after extubation in hypercapnic patients with chronic respiratory disorders: randomised controlled trial. Lancet Vol.374, No,9695, pp. 1082-1088, ISSN 0140-6736

Friedman, S. \& Goffin, FB. (1966). Abductor vocal weakness in myasthenia gravis: report of a case. Laryngoscope Vol. 76, No.9, pp. 1520-1523, ISSN 0023-852X

García Río F, Prados C, Díez Tejedor E, Díaz Lobato S, Alvarez-Sala R, Villamor J, Pino JM. (1994). Breathing pattern and central ventilatory drive in mild and moderate generalised myasthenia gravis. Thorax Vol.49, No.7, pp. 703-706, ISSN 0040-6376

Garcia-Pachon, E.; Casan, P. \& Sanchis, J. (1996). Myasthenia gravis and upper airway dysfunction. Chest Vol.110, No.4, pp. 1127-1128, ISSN 0012-3692

Gracey, DR.; Divertie, MB., Howard, FM Jr. (1983). Mechanical ventilation for respiratory failure in myasthenia gravis. Two-year experience with 22 patients. Mayo Clinic Proceedings Vol.58, No.9, pp. 597-602, ISSN 0025-6196

Hanson; JA.; Lueck, CJ., Thomas, DJ. (1996). Myasthenia gravis presenting with stridor. Thorax Vol.51, No.1. pp. 108-109, ISSN 0040-6376

Hardy, KA. \& Anderson, BD. (1996). Noninvasive clearance of airway secretions. Respiratory Care Clinics of North America Vol.2, No.2, pp. 323-345, ISSN 1078-5337

Hart, N.; Polkey, MI., Sharshar, T., Falaize, L., Fauroux, B., Raphaël, JC. \& Lofaso, F. (2003). Limitations of sniff nasal pressure in patients with severe neuromuscular weakness. Journal of Neurology, Neurosurgery and Psychiatry Vol.74, No.12, pp. 16851687, ISSN 0022-3050

Hill, NS.; Brennan, J., Garpestad, E.\& Nava, S. (2007). Noninvasive ventilation in acute respiratory failure. Critical Care Medicine Vol.35, No.10, pp. 2402-2407, ISSN 00903493

Hudspeth, MP.; Holden, KR. \& Crawford, TO. (2006). The "slurp" test: bedside evaluation of bulbar muscle fatigue. Pediatrics Vol.118, No.2, pp: e530-533, ISSN 1098-4275

Jaretzki, A 3rd,; Barohn, RJ., Ernstoff, RM., Kaminski, HJ., Keesey, JC., Penn, AS. \& Sanders, DB. (2000). Myasthenia gravis: recommendations for clinical research standards. Task Force of the Medical Scientific Advisory Board of the Myasthenia Gravis Foundation of America. Neurology Vol.55, No.1, pp. 16-23, ISSN 0028-3878

Juel, VC. (2004). Myasthenia gravis: management of myasthenic crisis and perioperative care. Seminars in Neurology Vol.24, No.1, pp. 75-81, ISSN 0271-8235

Kato, K.; Sato, N., Takeda, S., Yamamoto, T., Munakata, R., Tsurumi, M., Suzuki, D., Yagi, K., Tanaka, K. \& Mizuno, K. (2009). Marked improvement of extensive atelectasis by unilateral application of the RTX respirator in elderly patients. Internal Medicine Vol.48, No.16, pp. 1419-1423, ISSN 0918-2918

Keesey, JC. (2004). Clinical evaluation and management of myasthenia gravis. Muscle and Nerve Vol.29, No.4, pp. 484-505, ISSN 0148-639X

Kelly, BJ. \& Luce, JM. (1991). The diagnosis and management of neuromuscular diseases causing respiratory failure. Chest Vol.99, No.6, pp. 1485-1494, ISSN 0012-3692 
Kirmani, JF.; Yahia, AM. \& Qureshi, AI. (2004). Myasthenic crisis. Current Treatment Options in Neurology Vol.6, No.1, pp. 3-15, ISSN 1092-8480

Lacomis, D. (2005) Myasthenic crisis. Neurocritical Care Vol.3, No.3, pp. 189-194, ISSN 15416933

Lewis, FR. (1980). Management of atelectasis and pneumonia. The Surgical Clinics of North America Vol. 60, No.6, pp. 1391-1401, ISSN 0039-6109

Liggett, SB.; Daughaday, CC., Senior, RM. (1988). Ipratropium in patients with COPD receiving cholinesterase inhibitors. Chest Vol.94, No.1, pp. 210-212, ISSN 0012-3692

Linton, DM. (2005). Cuirass ventilation: a review and update. Critical Care and resuscitation Vol.7, No.1, pp. 22-28, ISSN 1441-2772

Mador, MJ. (1998). Weaning from mechanical ventilation: what have we learned and what do we still need to know? Chest Vol.114, No.3, pp.672-674, ISSN 0012-3692

Mayer, SA. (1997). Intensive care of the myasthenic patient. Neurology Vol.48, No.Suppl5, pp. S70-S75, ISSN 0028-3878

Martínez-Llorens, J.; Ausín, P., Roig, A., Balañá, A., Admetlló, M., Muñoz, L. \& Gea, J. (2011). Nasal inspiratory pressure: an alternative for the assessment of inspiratory muscle strength? Archivos de Bronconeumología Vol.47, No.4, pp. 169-175, ISSN 03002896

Mier-Jedrzejowicz, AK.; Brophy, C. \& Green, M. (1988). Respiratory muscle function in myasthenia gravis. American Review of Respiratory Disease Vol.138, No.4, pp. 867-873, ISSN 0003-0805

Mier, A.; Laroche, C. \& Green, M. (1990). Unsuspected myasthenia gravis presenting as respiratory failure. Thorax Vol.45, No.5, pp.422-423, ISSN 0040-6376

Murthy, JM.; Meena, AK., Chowdary, GV.\& Naryanan JT. (2005). Myasthenic crisis: clinical features, complications and mortality. Neurology India Vol.53, No.1, pp. 37-40, ISSN 0028-3886

Nocturnal oxygen therapy trial group. (1980). Continuous or nocturnal oxygen therapy in hypoxemic chronic obstructive lung disease: a clinical trial Annals of Internal Medicine Vol.93, No.3, pp. 391-398, ISSN 0013-4819

Namen, AM.; Ely, EW., Tatter, SB., Case, LD., Lucia, MA, Smith A, Landry S, Wilson JA, Glazier SS, Branch CL, Kelly DL, Bowton DL \& Haponik, EF. (2001). Predictors of successful extubation in neurosurgical patients. American Journal of Respiratory and Critical Care Medicine Vol.163, pp. 658-664, ISSN 1073-449X

No authors. (1991). AARC (American Association for Respiratory Care) clinical practice guideline: Incentive spirometry. Respiratory Care Vol.36, No.12, pp. 1402-1405, ISSN 0020-1324

O'Riordan, JI.; Miller, DH., Mottershead, JP., Hirsch, NP. \& Howard RS. (1998). The management and outcome of patients with myasthenia gravis treated acutely in a neurological intensive care unit. European Journal of Neurology Vol.5, No.2, pp. 137142, ISSN 1351-5101

Pascuzzi, RM., Coslett, HB. \& Johns, TR. (1984). Long-term corticosteroid treatment of myasthenia gravis: report of 116 patients. Annals of Neurology Vol.15, No.3, pp. 291298, ISSN 0364-5134

Perez, T. (2006). Neuromuscular disorders - assessment of the respiratory muscles. Revue Neurologique Vol.162, No.4, pp. 437-444, ISSN 0035-3787

Phillips LH. The epidemiology of myasthenia gravis. (2004). Seminars in Neurology Vol.24, No.1, pp. 17-20. ISSN 0271-8235 
Plauche, WC. (1991). Myasthenia gravis in mothers and their newborns. Clinical Obstetrics and Gynecology Vol.34, No.1, pp. 82-99, ISSN 0009-9201

Prigent H, Orlikowski D, Letilly N, Falaize L, Annane D, Sharshar T, Lofaso F. (2011). Vital capacity versus maximal inspiratory pressure in patients with Guillain-Barré syndrome and myasthenia gravis. Neurocrit Care Jul 12. [Epub ahead of print], ISSN 1541-6933

Phillips, LH 2nd. \& Torner JC. (1996). Epidemiologic evidence for a changing natural history of myasthenia gravis. Neurology Vol.47, No.5, pp. 1233-1238, ISSN 0028-3878

Polkey, MI.; Lyall, RA., Green, M., Nigel Leigh, P. \& Moxham J. (1998). Expiratory muscle function in amyotrophic lateral sclerosis. American Journal of Respiratory and Critical Care Medicine Vol.158, No.3, pp. 734-741, ISSN 1073-449X

Prigent, H.; Lejaille, M., Falaize, L., Louis, A., Ruquet, M., Fauroux, B., Raphael, JC. \& Lofaso F. (2004). Assessing inspiratory muscle strength by sniff nasal inspiratory pressure. Neurocrit Care Vol.1, No.4, pp. 475-478 ISSN 1541-6933

Putman, MT. \& Wise, RA. (1996). Myasthenia gravis and upper airway obstruction. Chest Vol.109, No.2, pp. 400-404, ISSN 0012-3692

Rabinstein A, Wijdicks EF. (2002). BiPAP in acute respiratory failure due to myasthenic crisis may prevent intubation. Neurology Vol.59, No.10, pp. 1647-1649, ISSN 00283878

Rabinstein, AA. \& Wijdicks, EF. (2003). Weaning from the ventilator using BiPAP in myasthenia gravis. Muscle and Nerve Vol.27, No.2, pp. 252-253, ISSN 0148-639X

Rabinstein, AA. \& Mueller-Kronast, N. (2005) Risk of extubation failure in patients with myasthenic crisis. Neurocrit Care Vol.3, No3, pp. 213-215, ISSN 1541-6933

Rabinstein, AA. \& Wijdicks, EF. (2003). Warning signs of imminent respiratory failure in neurological patients. Seminars in Neurology Vol.23, No.1, pp. 97-104, ISSN 02718235

Rieder, P., Louis, M., Jolliet, P. \& Chevrolet, JC. (1995). The repeated measurement of vital capacity is a poor predictor of the need for mechanical ventilation in myasthenia gravis. Intensive Care Medicine Vol.21, No.8, pp. 663-668, ISSN 0342-4642

Saeed, T. \& Patel, S. (2011). Use of non invasive ventilation to avoid re-intubation in myasthenia gravis; a case report and review of literature. Journal of the Pakistan Medical Association Vol.61, No.3, pp. 293-295, ISSN 0030-9982

Salam, A.; Tilluckdharry, L., Amoateng-Adjepong, Y. \& Manthous CA. (2004). Neurologic status, cough, secretions and extubation outcomes. Intensive Care Medicine Vol.30, No.7, pp. 1334-1339, ISSN 0342-4642

Selsby, D. \& Jones, JG. (1990) Some physiological and clinical aspects of chest physiotherapy. British Journal of Anaesthesia Vol.64, No.5, pp. 621-631, ISSN 00070912

Seneviratne, J.; Mandrekar, J., Wijdicks, EF. \& Rabinstein, AA. (2008). Predictors of extubation failure in myasthenic crisis. Archives of Neurology Vol.65, No.7, pp. 929933, ISSN 0003-9942

Seneviratne, J.; Mandrekar, J., Wijdicks, EF.\& Rabinstein, AA. (2008). Noninvasive ventilation in myasthenic crisis. Archives of Neurology Vol.65, No.1, pp. 54-58, ISSN 0003-9942

Soliman, MG.; Higgins, SE., El-Kabir, DR., Davidson, AC., Williams, AJ. \& Howard, RS. (2005). Non-invasive assessment of respiratory muscle strength in patients with 
previous poliomyelitis. Respiratory Medicine Vol.99, No.10, pp. 1217-1222, ISSN 0954-6111

Steier, J.; Kaul, S., Seymour, J., Jolley, C., Rafferty, G., Man, W., Luo, YM., Roughton, M., Polkey, MI. \& Moxham, J. (2007). The value of multiple tests of respiratory muscle strength. Thorax Vol.62, No.11, pp. 975-980, ISSN 0040-6376

Suárez, AA.; Pessolano, FA., Monteiro, SG., Ferreyra, G., Capria, ME., Mesa, L., Dubrovsky, A. \& De Vito, EL. (2002). Peak flow and peak cough flow in the evaluation of expiratory muscle weakness and bulbar impairment in patients with neuromuscular disease. American Journal of Physical Medicine and Rehabilitation Vol.81, No.7, pp. 506-511, ISSN 0894-9115

Szathmáry, I.; Magyar, P. \& Szobor, A. (1981). Myasthenia gravis: protective effect of ipratropium bromide (Atrovent) on airways obstruction caused by edrophonium chloride (Tensilon). European Neurology Vol.20, No.1, pp. 56-61, ISSN 0014-3022

Thomas, CE.; Mayer, SA., Gungor, Y., Swarup, R., Webster, EA., Chang, I., Brannagan, TH., Fink, ME. \& Rowland LP. (1997). Myasthenic crisis: clinical features, mortality, complications, and risk factors for prolonged intubation. Neurology Vol.48, No.5, pp. 1253-1260, ISSN 0028-3878

Toussaint, M.; De Win, H., Steens, M. \& Soudon P. (2003). Effect of intrapulmonary percussive ventilation on mucus clearance in duchenne muscular dystrophy patients: a preliminary report. Respiratory Care Vol.48, No.10, pp. 940-947, ISSN 0020-1324

Varelas,PN.; Chua, HC., Natterman, J., Barmadia, L., Zimmerman, P., Yahia, A., Ulatowski, J., Bhardwaj, A., Williams, MA. \& Hanley, DF. (2002). Ventilatory care in myasthenia gravis crisis: assessing the baseline adverse event rate. Critical Care Medicine Vol.30, pp. 2663-2668, ISSN 0090-3943

Vianello, A.; Donà, A., Salvador, V. \& Ori C. (2010). Extubation of patients with neuromuscular weakness: a routine step or a challenging procedure? Chest Vol.138, No.4, pp. 1026-1027, ISSN 0012-3692

Vianello, A.; Arcaro, G., Braccioni, F., Gallan, F., Marchi, MR., Chizio, S., Zampieri, D., Pegoraro, E. \& Salvador V. (2011). Prevention of extubation failure in high-risk patients with neuromuscular disease. Journal of Critical Care Vol.26, pp. 517-524, ISSN 1557-8615

Windisch, W.; Hennings, E., Sorichter, S., Hamm, H. \& Criée, CP. (2004). Peak or plateau maximal inspiratory mouth pressure: which is best? The European Respiratory Journal Vol.23, pp. 708-713, ISSN 0903-1936

Wendell, LC. \& Levine, JM. (2011) Myasthenic Crisis. The Neurohospitalist Vol.1, pp. 16-22, ISSN 1941-8744

Wilson, SR.; Quantz, MA., Strong, MJ. \& Ahmad, D. (2005). Increasing peak expiratory flow time in amyotrophic lateral sclerosis. Chest Vol.127, No.1, pp.156-160, 0012-3692

Wu, JY.; Kuo, PH., Fan, PC., Wu, HD., Shih, FY. \& Yang, PC. (2009). The role of non-invasive ventilation and factors predicting extubation outcome in myasthenic crisis. Neurocrit Care Vol.10, No.1, pp. 35-42, ISSN 1541-6933 


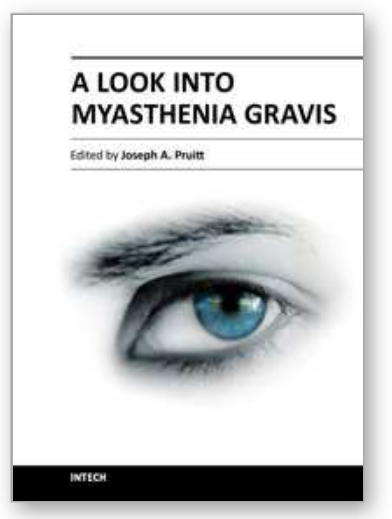

\author{
A Look into Myasthenia Gravis \\ Edited by Dr. Joseph A. Pruitt
}

ISBN 978-953-307-821-2

Hard cover, 106 pages

Publisher InTech

Published online 20, January, 2012

Published in print edition January, 2012

Myasthenia gravis is presently an incurable antibody-mediated autoimmune disorder characterized by generalized voluntary skeletal muscle weakness. The cause of the weakness is a defect at the neuromuscular junction level, in which autoimmune antibodies block the receptors responsible for initiating muscular contraction. Literally translated from its Latin and Greek etymological roots, myasthenia gravis means "grave muscle weakness". Fortunately, advances in modern medicine have resulted in a reduction of the truly "grave" outcomes for those inflicted but, without a cure, the gravity surrounding the disease remains

\title{
How to reference
}

In order to correctly reference this scholarly work, feel free to copy and paste the following:

Ping-Hung Kuo and Pi-Chuan Fan (2012). Respiratory Care for Myasthenic Crisis, A Look into Myasthenia Gravis, Dr. Joseph A. Pruitt (Ed.), ISBN: 978-953-307-821-2, InTech, Available from:

http://www.intechopen.com/books/a-look-into-myasthenia-gravis/respiratory-care-for-myasthenic-crisis

\section{INTECH}

open science | open minds

\section{InTech Europe}

University Campus STeP Ri

Slavka Krautzeka 83/A

51000 Rijeka, Croatia

Phone: +385 (51) 770447

Fax: +385 (51) 686166

www.intechopen.com

\section{InTech China}

Unit 405, Office Block, Hotel Equatorial Shanghai

No.65, Yan An Road (West), Shanghai, 200040, China

中国上海市延安西路65号上海国际贵都大饭店办公楼 405 单元

Phone: +86-21-62489820

Fax: $+86-21-62489821$ 
(C) 2012 The Author(s). Licensee IntechOpen. This is an open access article distributed under the terms of the Creative Commons Attribution 3.0 License, which permits unrestricted use, distribution, and reproduction in any medium, provided the original work is properly cited. 